\title{
EFFECTS OF INTRASPECIFIC COMPETITION AND FOOD DEPRIVATION ON THE IMMATURE PHASE OF ASCIA MONUSTE ORSEIS (LEPIDOPTERA, PIERIDAE)
}

\author{
Helen C. H. Barros-Bellanda ${ }^{1}$ \\ Fernando Sérgio Zucoloto ${ }^{1}$
}

\begin{abstract}
The effect of intraspecific competition for food on larvae and of food deprivation for $24 \mathrm{~h}$ on $2 \mathrm{nd}$ and 4th instars of Ascia monuste orseis (Godart, 1819) was investigated. Intraspecific competition for food during the immature phase leads to long pupation time, high larval mortality, reduced adult weight, and reduced number of eggs per female. In food deprivation experiments, the major differences in $A$. monuste orseis performance were long pupation time in the group that was deprived during the 2nd instar; and a negative effect on reproduction in the group that was deprived during the 4th instar, with reduced adult weight. Both food deprived periods tested are critical, and deprivation during the 2 nd instar seems to have an effect as drastic as during the 4th instar because it directly affects larvae survival. Immatures can resist food deprivation for $24 \mathrm{~h}$ during the $2 \mathrm{nd}$ and 4 th instars (low mortality), have a compensatory behaviour (high ingestion and biomass gain) during the 5th instar, and do not demonstrate cannibalistic behaviour during food deprivation.
\end{abstract}

KEYWORDS. Compensatory behaviour, food deprivation, Insecta.

\section{INTRODUCTION}

In general, lepidopterans are specialized in the selection of oviposition places. However, some "mistakes" are frequently observed. These "mistakes" are ovipositions on plant species outside the normal range of acceptable hosts (THOMPSON \& PELLMYR, 1991) and/or ovipositions that affect larval survival.

Ascia monuste orseis (Godart, 1819), known in Brazil as cabbage caterpillar, is one of the most important consumers of Brassicaceae in the Neotropical region. It is known that 5th instar caterpillars have a high mobility and can move to another plant, but newly hatched caterpillars can not do it. Because 1st and 2nd instars ingest a small amount of food, intraspecific competition for food occurred only during the final three instars. In nature, larve migrate to a new food resource when there is group competition. Some ovipositional "mistakes" are frequently observed e. g. large egg clutches, egg-laying on small or old leaves, on small or old plants and egg-laying on the stem. The consequences of these "mistakes" are immature migration to obtain a new food resource and food deprivation. The

1. Depto de Biologia (FFCL-RP), Universidade de São Paulo, Av. Bandeirantes 3900, 14049-901, Ribeirão Preto, SP, Brasil. 
aims are to investigate the effects of intraspecific competition for food on the immature phase, the effects of $24 \mathrm{~h}$ food deprivation on $2 \mathrm{nd}$ and 4 th instar caterpillars, and to obtain if insects are able to make up the nutritional deficit incurred during deprivation once they have access to food.

\section{MATERIAL AND METHODS}

Eggs were collected from kale Brassica oleraceae L. var. acephala DC leaves in a garden to which no pesticide had been applied, located $100 \mathrm{~m}$ from the Departamento de Biologia, Universidade de São Paulo ( $21^{\circ} 05^{\prime}$ S, $47^{\circ} 50^{\prime} \mathrm{W}$ ) São Paulo, Brazil.

Intraspecific competition (group E1) was obtained using the same number of control group caterpillars (C1), but using a leaf cut in half longitudinally. Food deprivation was tested on 2nd instar and on 4th instar caterpillars. In both groups (E2 and E3), caterpillars did not eat for $24 \mathrm{~h}$ at the beginning of the respectively 2 nd instar and 4 th instar.

The parameters measured were: time for pupation (days), adult weight (male and female, mg), number of adults per box, number of eggs per female, incorporated biomass (mg), ingestion (mg), faeces $(\mathrm{mg})$, and digestive indexes: approximate digestibility (AD, \%), efficiency in converting ingested food (ECI, \%) and efficiency in converting digested food (ECD, \%), tested during the 5th instar. Approximate digestibility [(ingestion-faeces)/ingestion], ECI [biomass gained/ingestion], and ECD [biomass gained/ (ingestion-faeces)] indexes were obtained by the methods of SLANSKY \& SCRIBER (1985).

Each group consisted of six boxes $(10 \times 10 \times 4 \mathrm{~cm})$ with seven newly hatched caterpillars each; it was necessary to maintain some reserve boxes. Plastic boxes were lined with paper towel (FeLIPE \& Zucoloto, 1993) and the food, one leaf per box $\left(\approx 150 \mathrm{~cm}^{2}\right)$ which was sufficient for $24 \mathrm{~h}$ without competition, it was changed daily. The boxes were placed in an incubator at $29 \pm 2{ }^{\circ} \mathrm{C}$; luminosity was provided by a fluorescent lamp (400 lux) for $10 \mathrm{~h}$ per day and humidity maintained at $\approx 80 \%$ (BARROS \& Zucoloto, 1999).

Emerged adults were placed in wooden cages $(80 \times 80 \times 80 \mathrm{~cm})$ and covered with a plastic net with a side opening used to introduce the butterflies and food. The cage contained a pot with kale and a glass plate $4 \mathrm{~cm}$ in diameter with a $10 \%$ sucrose solution and a blue dye (FeliPE \& ZuCOLOTO, 1993), lined with cotton to facilitate feeding (Huang \& Renwick, 1993). Preliminary tests indicated that A. monuste orseis females were attracted to the feeding container when blue or yellow dye was used, and that they ingested the sucrose solution dye (Felipe \& Zucoloto, 1993). The cages were left in a protected site in the field and exposed to sunlight from $10 \mathrm{~h}$ AM to $2 \mathrm{~h} \mathrm{PM}$ for the butterflies to mate and oviposit (BARRos \& ZuColoto, 1999).

Ingestion was determined on the basis of amount of food consumed by caterpillars during the fifth instar. Each caterpillar was placed individually in a standardised glass tube containing sufficient food for $24 \mathrm{~h}(\mathrm{n}=10)$; the food was renewed daily. Leaves picked in the garden were used to feed the caterpillars, each one cut in half longitudinally, one half was supplied as food and the other half was used as a control to determine the amount of dry matter present in the leaf (FeliPe \& Zucoloto, 1993; BARRos \& Zucoloto, 1999). Most food consumption and larval growth occur during the last instar, and the performance calculated during these instars are often representative of the whole immature stage (Khalsa et al., 1979; Scriber \& Slansky, 1981; Barros \& Zucoloto, 1999). Biomass was determined on the basis of the mass incorporated by the same 10 caterpillars during the fifth instar. To determine the initial mass of the caterpillars, also evaluated on the basis of dry weight, five caterpillars at the beginning of the fifth instar and of a similar wet weight were used. All material used to calculate dry weight (leaves, caterpillars, pupae, faeces) was placed in an incubator at $80^{\circ} \mathrm{C}$ for $24 \mathrm{~h}$ (BARROs \& Zucoloto, 1999).

The parameter time for pupation was obtained by recording the time and counting the number of pupae formed in each box $(\mathrm{n}=6)$ at two fixed times of the day ( $8 \mathrm{~h} \mathrm{AM}$ and $5 \mathrm{~h}$ PM). The number of adults per box $(n=6)$ was the number of emerged adults per box; there were seven newly hatched caterpillars per box at the beginning of the experiment, and therefore larval and pupal mortality was evaluated as a whole. At the end of pupation, after the emergence of adults, one or two adults of each sex per box/group were separated for the determination of dry weight $(\mathrm{n}=10)$.

Data were analyzed statistically by t-test (SigmaStat for Windows, 1994, Jandel Co., San Rafael, California), with $\alpha=0.05$. 


\section{RESULTS}

The caterpillars were on food competition for six days. Most parameters of intraspecific competition for food (tab. I) differed significantly between the control group (C1) and the competition group (E1). Final mean caterpillar weight was $98.7 \mathrm{mg}$ and $91.5 \mathrm{mg}$ for the $\mathrm{C} 1$ and E1 groups, respectively. The food deprivation on 2 nd instar (tab. I) showed that the parameters time for pupation, ingestion and biomass incorporated were significantly different. Final mean caterpillar weight was $101.6 \mathrm{mg}$ and $102.4 \mathrm{mg}$ for $\mathrm{C} 2$ and $\mathrm{E} 2$ groups, respectively. The food deprivation on 4th instar (tab. I) showed that the parameters imago weight (female and male), number of eggs per female, ingestion and $\mathrm{AD}$ were significantly different. Final mean caterpillar weight was $104.5 \mathrm{mg}$ and $98.3 \mathrm{mg}$ for C3 group and E3 groups, respectively.

The 5th instar caterpillars of the food deprived experiments were able to compensate with greater ingestion and incorporated biomass. A. monuste orseis immatures were able to resist food deprivation during the 2nd and 4th instar for $24 \mathrm{~h}$ (high emergence, tab. I), and did not demonstrate cannibalistic behaviour during food deprivation.

\section{DISCUSSION}

Food competition on A. monuste orseis must not be a strong selective pressure in nature, because it was observed that the larvae prefer migration to a new plant in the presence of high larval density. This is an advantageous behaviour because the kale planting area is always large (BARROS \& ZuCOLOTO, 1999) and larval migration is often a successful event.

Intraspecific competition for food during the larval phase leads to serious problems for A. monuste orseis performance as described for others insects, e. g. long time for pupation and high larval mortality (PETERS \& BARBOSA, 1977) and reduced adult weight and number of eggs per female (BANKS \& THOMPSON, 1987; HiRSCHBERGER, 1999). Competition experiments in the laboratory showed that small females of $A$. monuste orseis cannot lay eggs (inviable reproductive strategy).

The production of a competitive adult (female and male) is important for the species success. The pupation decision must consider the biomass gained during the immature phase; if a caterpillar is in its final instar with a low weight, it is necessary to evaluate the potential cost of a longer development and the cost of reduced adult weight (SLANSKY, 1980). In some cases female weight or size is correlated positively with fitness parameters (egg production) (Haukioja \& NeUvonen, 1985; Marshall, 1990; Visser, 1994; TAMmaru, 1998). In males the influence of body size is even more difficult to assess (HIRSCHBERGER, 1999). Females are heavier than males in general (MuKERJI \& GuPPY, 1970; ВЕСКWITH, 1976), and attain their greater weight by growing for a longer period of time, thus consuming more food (BECKWITH, 1976). In competition situations, females must have more nutritional problems than males, as observed for A. monuste orseis.

Caterpillars from a competition group showed a high approximate digestibility (AD), but a lower efficiency in converting digested food (ECD) during the 5th instar, indicating that these caterpillars were less selective in feeding. Low ECD value indicates a high caterpillar activity and a low rate of biomass gained (CORBITT et al., 1996).

Food deprivation for $24 \mathrm{~h}$ during the $2 \mathrm{nd}$ instar showed a negative effect on immature performance, with a longer time for pupation, which exposes the caterpillars to negative biotic and abiotic conditions for survival in the field, e. g. risks of parasitism, predation and 
temperature desiccation. The level of $A$. monuste orseis immature parasitism by Cortesia ayerzai (Brèthes) (Hymenoptera, Braconidae) is high, especially at the beginning of the larval phase (GobBi et al., 1990), and there is also the risk of predation by spiders and birds. Food deprivation for $24 \mathrm{~h}$ during the 4 th instar had a negative effect on immature performance, with a decrease in number of eggs per females, which represents a lower genetic contribution to the next generation. The adults were less heavy, with a direct effect on species reproduction.

Reports on lepidopteran larvae have indicated that food deprivation can have complex and subtle effects on various digestive indexes and utilization efficiency, as well as on feeding behaviour (SCHROEDER, 1976; GRABSTEIN \& SCRIBER, 1982). Compensatory responses to food deprivation can be an alteration in insect rate of consumption in order to ingest sufficient nutrients, and/or an alteration in the digestive and metabolic efficiencies to make best use of ingested nutrients (SIMPSON \& SiMPSON, 1990). The first example of compensation occurred in the present food deprivation experiments. Previously deprived

Table I. Comparative performance of A. monuste orseis (Godart, 1819) caterpillars that (1) were not in intraspecific competition (control group, C1) and were in competition (experimental group, E1); (2) were not food deprived during the 2nd instar (control group, C2) and were food deprived during the 2nd instar (experimental group, E2); and (3) were not food deprived during the 4th instar (control group, C3) and were food deprived during the 4th instar (experimental group, E3). The digestive indexes indicate performance of 5th instar. Initial 5th instar weight $(\mathrm{Cl}=26.2 \mathrm{mg} \pm 4.2, \mathrm{E} 1=16.6 \mathrm{mg} \pm 5.0 ; \mathrm{C} 2=24.2 \mathrm{mg}$ $\pm 5.2, \mathrm{E} 2=17.2 \mathrm{mg} \pm 4.0$; and $\mathrm{C} 3=23.5 \mathrm{mg} \pm 4.7, \mathrm{E} 3=15.3 \mathrm{mg} \pm 3.0) ; \mathrm{n}=10$; means $\pm \mathrm{SD}$ followed by different letters differed significantly on comparative groups (t-test, $\mathrm{P}<0.05$ ). AD, approximate digestibility; ECI, efficiency in converting ingested food; ECD, efficiency in converting digested food.

\begin{tabular}{|c|c|c|c|c|c|c|}
\hline & $\mathrm{Cl}$ & $\mathrm{E} 1$ & $\mathrm{C} 2$ & E2 & $\mathrm{C} 3$ & E3 \\
\hline $\begin{array}{l}\text { Imago weight } \\
\text { female (mg) }\end{array}$ & $71.3 \pm 9.0 \mathrm{a}$ & $56.3 \pm 14.9 b$ & $68.4 \pm 6.1 \mathrm{a}$ & $66.0 \pm 7.2 \mathrm{a}$ & $68.0 \pm 3.3 \mathrm{a}$ & $63.0 \pm 4.2 \mathrm{~b}$ \\
\hline $\begin{array}{l}\text { Imago weight } \\
\text { male (mg) }\end{array}$ & $58.3 \pm 6.9 \mathrm{a}$ & $42.4 \pm 12.8 b$ & $59.5 \pm 3.8 \mathrm{a}$ & $61.5 \pm 6.6 \mathrm{a}$ & $58.9 \pm 3.0 \mathrm{a}$ & $55.0 \pm 2.6 \mathrm{~b}$ \\
\hline $\begin{array}{l}\text { Time for } \\
\text { Pupation (mg) }\end{array}$ & $10.2 \pm 0.4 \mathrm{a}$ & $11.5 \pm 0.8 b$ & $10.0 \pm 0.4 a$ & $11.5 \pm 0.5 b$ & $10.5 \pm 0.5 \mathrm{a}$ & $11.0 \pm 0.5$ \\
\hline $\begin{array}{l}\text { Number of } \\
\text { adults per box }\end{array}$ & $6.0 \pm 0.7 \mathrm{a}$ & $5.0 \pm 0.8 b$ & $6.2 \pm 0.8 \mathrm{a}$ & $5.9 \pm 0.6 \mathrm{a}$ & $6.1 \pm 0.8 \mathrm{a}$ & $5.8 \pm 0.7 \mathrm{a}$ \\
\hline $\begin{array}{l}\text { Number of eggs } \\
\text { per female }\end{array}$ & $77.0 \pm 12.6 \mathrm{a}$ & $44.0 \pm 27.3 b$ & $105.7 \pm 45.3 \mathrm{a}$ & $80.4 \pm 31.6 a$ & $100.4 \pm 29.6 \mathrm{a}$ & $67.0 \pm 14.6 \mathrm{~b}$ \\
\hline $\mathrm{AD}(\%)$ & $40.5 \pm 5.2 \mathrm{a}$ & $47.0 \pm 6.2 \mathrm{~b}$ & $40.5 \pm 8.6 \mathrm{a}$ & $41.5 \pm 8.0 \mathrm{a}$ & $44.0 \pm 4.0 \mathrm{a}$ & $49.0 \pm 5.1 \mathrm{~b}$ \\
\hline $\mathrm{ECI}(\%)$ & $18.0 \pm 1.9 \mathrm{a}$ & $18.8 \pm 2.8 \mathrm{a}$ & $20.8 \pm 4.8 \mathrm{a}$ & $21.7 \pm 5.5 \mathrm{a}$ & $21.8 \pm 6.7 \mathrm{a}$ & $21.7 \pm 2.5 \mathrm{a}$ \\
\hline $\mathrm{ECD}(\%)$ & $44.5 \pm 9.4 a$ & $40.0 \pm 8.8 \mathrm{a}$ & $51.5 \pm 10.0 \mathrm{a}$ & $52.2 \pm 11.9 a$ & $49.7 \pm 9.0 \mathrm{a}$ & $44.8 \pm 8.2 \mathrm{a}$ \\
\hline Ingestion (mg) & $404.1 \pm 33.5 \mathrm{a}$ & $397.3 \pm 53.6 \mathrm{a}$ & $370.0 \pm 22.7 \mathrm{a}$ & $394.4 \pm 20.7$ & $368.5 \pm 10.9 \mathrm{a}$ & $382.8 \pm 13.0 \mathrm{~b}$ \\
\hline Faeces (mg) & $239.1 \pm 16.1 \mathrm{a}$ & $210.2 \pm 33.9 \mathrm{a}$ & $220.0 \pm 6.3 \mathrm{a}$ & $230.8 \pm 12.2 \mathrm{a}$ & $206.9 \pm 13.9 \mathrm{a}$ & $197.6 \pm 10.0 \mathrm{a}$ \\
\hline Biomass (mg) & $72.5 \pm 10.0 \mathrm{a}$ & $74.9 \pm 12.0 \mathrm{a}$ & $77.4 \pm 5.0 \mathrm{a}$ & $85.2 \pm 4.2 b$ & $80.5 \pm 6.7 \mathrm{a}$ & $83.0 \pm 8.3 \mathrm{a}$ \\
\hline
\end{tabular}


larvae compensated by eating larger, longer, and more frequent meals (BOwDAN, 1988). Louveaux, 1977 apud SiMPSON \& SIMPSON (1990) demonstrated that $24 \mathrm{~h}$ deprived nymphs compensated almost exactly for the amount which had been eaten during the deprivation period by increased consumption over the following days.

Food deprivation increases locomotor activity, apparently in relation to the level of metabolic reserves held by the insect (BROwNE, 1975; CALOw, 1977). The detailed behaviour mechanisms of increased consumption following a period without food are not well known.

Food deprivation for $24 \mathrm{~h}$ showed a direct effect on the survival of $A$. monuste orseis immatures when imposed at the beginning of development (2nd instar) and an indirect effect on immatures when imposed during the 4th instar. Both periods tested are critical, but the food deprivation during 2 nd instar seems to have an effect as drastic to $A$. monuste orseis as during the 4th instar, because it causes an increase in larval phase duration. An increase in time to pupation in the field can pose many risks to immature survival (direct effect on survival).

\section{REFERENCES}

Banks, M. J. \& Thompson, D. J. 1987. Lifetime reproductive success of females of the damselfly Coenagrion puella. J. Anim. Ecol., Oxford, 56:815-832.

Barros, H. C. H. \& Zucoloto, F. S. 1999. Performance and host preference of Ascia monuste (Lepidoptera, Pieridae). J. Insect Physiol., Oxford, 45:7-14.

Beckwith, R. C. 1976. Influence of foliage on the Douglas-fir tuddock moth. Envir. Ent., Lanham, 5:73-77.

BowdAn, E. 1988. The effect of deprivation on microstructure of feeding by the tobacco hornworm caterpillar. J. Insect Behaviour, New York, 1:31.

Browne, L. B. 1975. Regulatory mechanisms in insect feeding. Adv. Insect Physiol., London, 11:1116.

CAlow, P. 1977. Ecology, evolution and energetics: A study in metabolic adaptation. Adv. Ecol. Res., London, 10:1-62.

CorbitT, T. S.; Bryning, S. et al. 1996. Reproductive, developmental and nutritional biology of the tomato moth, Lacanobia oleracea (Lepidoptera, Noctuidae) reared on artificial diet. Bull. ent. Res., London, 86:647-657.

Felipe, M. C. \& Zucoloto, F. S. 1993. Estudos de alguns aspectos da alimentação em Ascia monuste Godart (Lepidoptera: Pieridae). Revta bras. Zool., Curitiba, 10(2):333-341.

GobBi, N.; Cunha, M. C. A. et al. 1990. Ovipositon pattern by Cotesia ayerzai (Hymenoptera, Braconidae) on Ascia monuste (Lepidoptera, Pieridae) under laboratory conditions. Entomophaga, Paris, 35(2):195-202.

Grabstein, E. M. \& Scriber, J. M. 1982. Host plant utilization by Hyalophora cercropia as affected by prior feeding experience. Entomologia exp. appl., Dordrecht, 32:262.

Haukioja, E. \& Neuvonen, S. 1985. The relationship between size and reproductive potential in male and female Epirrita autumnata (Lepidoptera, Geometridae). Ecol. Ent., Oxford, 10:267-270.

Hirschberger, P. 1999. Larval population density affects female weight and fecundity in the dung beetle Aphodius afer. Ecol. Ent., Oxford, 24:316-322.

Hunang, H. \& Renwick, J. A. A. 1993. Differential selection of host plants by two Pieris species: the role of oviposition stimulants and deterrents. Entomologia exp. appl., Dordrecht, 68:59-69.

Khalsa, M. S.; Kogan, M. \& Luckman, W. H. 1979. Autographa precationis in relation to soybean: Life history, and food intake and utilization under controlled conditions. Envir. Ent., Lanham, 8:117122.

Marshall, L. D. 1990. Intraspecific variation in reproductive effort by female Parapediasia teterrella (Lepidoptera, Pyralidae) and its relation to body size. Can. J. Zool., Ottawa, 68:44-48.

MukerJ, M. K. \& Guppy, J. C. A. 1970. A quantitative study of food consumption and growth in Pseudaletia unipuncta. Can. Ent., Ottawa, 102:1179-1188. 
Peters, T. M. \& Barbosa, P. 1977. Influence of population density on size, fecundity and developmental rate of insects in culture. A. Rev. Ent., Palo Alto, 22:431-450.

SCHROEDER, L. A. 1976. Effect of food deprivation on the efficiency of utilization of dry matter, energy and nitrogen by larvae of the Calocalpe undulata. Ann. ent. Soc. Am., Lanham, 69(1):55-58.

Scriber, J. M. \& Slansky, F., JR. 1981. The nutritional ecology of immatures insects. A. Rev. Ent., Palo Alto, 26:183-211.

Simpson, S. J. \& Simpson, C. L. 1990. The mechanisms of nutritional compensation by phytophagous insects. In: Bernays, E. A. ed. Insect-Plant Interaction, Cleveland, CRC Press. p.111-160.

Slansky, F., JR. 1980. Quantitative food utilization and reproductive allocation by adult milkweeds bugs, Oncopeltus fasciatus. Physiol. Ent., Oxford, 18:395-403.

Slansky, F., Jr. \& Scriber, J. M. 1985. Food consumption and utilization. In: Kerkut, G. A. \& Gilbert, L. I. ed. Comprehensive Insect Physiology, Biochemistry and Pharmacology IV. Oxford, Pergamon. p.87-163.

Tammaru, T. 1998. Determination of adult size in a folivorous moth: constraints at instar level? Ecol. Ent., Oxford, 23:80-89.

Thompson, J. N. \& Pellmyr, O. 1991. Evolution of oviposition behaviour and host preference in Lepidoptera. A. Rev. Ent., Palo Alto, 36:65-89.

VISSER, M. E. 1994. The importance of being large: the relationship between size and fitness in females of the parasitoid Aphaereta minuta (Hymenoptera, Braconidae). J. Anim. Ecol., Oxford, 63:963978.

Recebido em 09.04.2001; aceito em 21.08.2001

Iheringia, Sér. Zool., Porto Alegre, 92(1):93-98, 31 de março de 2002 